
\title{
Relationships between Nurses' Resilience, Emotional Labor, Turnover Intention, Job Involvement, Organizational Commitment and Burnout
}

\author{
Ju, Se Jin' and Oh, Doonam²* \\ 'Department of Nursing, Namseoul University, Chunan, Korea; lovepdd@nsu.ac.kr \\ 2Department of Nursing, Hoseo University, Asan, Korea; doonoh@hoseo.edu
}

\begin{abstract}
Objectives: To explore the correlation of emotional labor, turnover intention, burnout, job involvement, organizational commitment and resilience among nurses and identify the factors affecting resilience. Methods/Statistical Analysis: The participants were 382 nurses within five years of clinical career who had a registered nurses license and involved at the Hospital Nurses Association's nationwide education program. A total of 382 questionnaires were collected from January to June 2015. Finally, 340 data that excluded 42 as improper responses were analyzed using t-test, ANOVA, Pearson correlation coefficient and Simple regression analysis. Findings: Resilience of nurses was positively correlated with job involvement and organizational commitment. It was negatively correlated with emotional labor, turnover intention and burnout. The variables significantly affected by resilience were emotional labor $(F=17.30, p<.001)$, job involvement $(F$ $=21.53, \mathrm{p}<.001)$, organizational commitment $(\mathrm{F}=28.11, \mathrm{p}<.001)$ and burnout $(\mathrm{F}=77.85, \mathrm{p}<.001)$. But resilience had no significant effect on turnover intention. Improvements/Applications: This study revealed that the important individual factor of resilience had a positive influence on organizational commitment. Thus, resilience should be actively promoted and a program developed to enhance the resilience of nurses.
\end{abstract}

Keywords: Burnout, Commitment, Emotional Labor, Nurse, Resilience, Turnover Intention

\section{Introduction}

Resilience is an important concept to serve as a nurse to adapt to the hospital environment ${ }^{1}$. Also despite the tremendous job stress, the high resilience nurse can be overcome and adapt to the business process and environment. Since nurses' turnover can reduce the level of nursing services and expertise in nursing and result in a waste of healthcare resources, much study has been carried out the factors affecting turnover intention. In this regard, researchers tried to make an integrative analysis of its association with such factors as stress, job satisfaction, organizational commitment and burnout for nurses 2 . Resilience refers to the ability to overcome the difficulties and make successful adjustment. The concept of resilience measured for children, adolescents, adults, seniors and research have been implemented the impact on the resilience ${ }^{4}$. However there were no study identified the resilience characteristics for nurses, moreover emotional labor, turnover intention, burnout, job involvement and organizational commitment have not yet been studied. It is therefore necessary to conduct research on the effects of resilience for nurses doing heavy emotional labor.

Turnover is the process through which staff leaves a business or organization and that business or organization replaces them. Turnover intention is a measurement of whether a business' or organization's employees plan to leave their positions or whether that organization plans to remove employees from positions. Turnover intention, like turnover itself, can be either voluntary or involuntary.

The purpose of this study was to measure resilience for nurses in clinical nursing practice and determined its influential relations with their turnover intention, job involvement, organizational commitment and burnout.

${ }^{*}$ Author for correspondence 
It aimed to provide the foundation for efficient nursing manpower management based on the concept of resilience. It also aimed to develop a prevention program that could not only help make interventional strategies for reducing difficulties nurses might have in performing their duties but also help improve the working environment and take a positive measure.

\section{Methods}

\subsection{Objective}

The purpose of this study is to determine the level of emotional labor, turnover intention, burnout, job involvement, organizational commitment and resilience and correlation among them for nurses and identify the factors affecting resilience. The specific objectives are as follows: 1 . To determine the level of emotional labor, turnover intention, burnout, job involvement, organizational commitment and resilience. 2. To assess the level of effects of resilience on emotional labor, turnover intention, burnout, job involvement and organizational commitment for nurses.

\subsection{Design of Research}

This is descriptive research to identify the influential factors among emotional labor, turnover intention, job involvement, organizational commitment, burnout and resilience.

\section{Subjects}

The subjects were nurses with three to five years of clinical career who had a registered nurses license and involved at the Hospital Nurses Association's nationwide education program. They were given explanation about this study before education and gave a written consent to participation in this study. A total of 382 questionnaires were collected - a sample of 132 persons with effect size 0.1 , significance level .05 and testability .95 , using a $G$ power 3.1.0 program. 340 data were finally analyzed and excluded 42 as improper responses.

\section{Research Instrument}

\subsection{Emotional Labor}

Emotional labor is a way of emotion regulation in which employees control their emotions and feelings at work.
$\operatorname{In}^{4}$ developed the emotional labor scale and used in this study. This scale was composed of nine items in a total of three sub-areas: Three items concerning the frequency of emotional labor, three concerning attention to emotional expression and three concerning emotional dissonance. It is a five-point Likert scale - 1 totally disagree to 5 strongly agree - with a higher score meaning heavier emotional labor.

\subsection{Turnover Intention}

Turnover intention was defined as individuals who receive compensation money as qualification terminate the membership of the organization.

In this study, it was a five-point scale with four items, with a higher score meaning a higher level of turnover intention. Reliability of the scale was Cronbach's alpha = .860. It was .799 in this study.

\subsection{Job Involvement}

Job involvement means being absorbed in or committed to one's job and refers to a personal sense of unity with a job. Job involvement refers to the psychological and emotional extent to which you participate in your work, profession and company beyond simply punching in, performing your tasks and punching out. In some instances, people become overly involved with their jobs, leading to stress.

This scale is developed by ${ }^{5}$ to hospital situations and nurses, used to measure job involvement in this study that was job involvement simplified seven items, 5 point Likert means the higher the score, the higher the degree of job involvement. Reliability was Cronbach's $\mathrm{a}=.736$ and in this study is .645

\subsection{Organizational Commitment}

Organizational commitment was the identification of individuals for the organization is defined as the relative degree of commitment.

Organizational commitment may be viewed as an organizational member's psychological attachment to the organization. Organizational commitment plays a very large role in determining whether a member will stay with the organization and zealously work towards organizational goals. Organizational commitment is the Three-Component Model (or TCM). The model argues that organizational commitment has three distinctive components: Affective commitment, continuance commitment, normative commitment. 
This scale is 15 items, identification 6 and attachment 6, years of service 3.7 point Likert means the higher the score, the higher the degree of organizational involvement. Reliability was Cronbach's a $=0.889$.

\subsection{Burnout}

Simple definition of burnout is the condition of someone who has become very physically and emotionally tired after doing a difficult job for a long time. So "Exhaustion can occurred people who work for a relative" and there were 3 features of exhaustion that was depletion of emotion, depersonalization and self-fulfillment deterioration of sentiment. In this study, burnout was measured using the Maslach Burnout Inventory (MBI) translated into Korean version by ${ }^{6}$. It was twenty items in a total of three sub-categories: Six items concerning physical burnout, seven items concerning affective burnout and seven items concerning mental burnout. It was a five point Likert scale, from 1 totally disagree to 5 strongly agree and a higher score meaning more serious burnout.

\subsection{Resilience}

Resilience means an ability to overcome difficulties and make successful adjustment ${ }^{\underline{T}}$. Psychological resilience is defined as an individual's ability to properly adapt to stress and adversity. Stress and adversity can come in the shape of family or relationship problems, health problems or workplace and financial worries, among others. Resilience should be considered a process, rather than a trait to be had. It is a process of individuation through a structured system with gradual discovery of personal and unique abilities.

In this study, it was measured using the resilience scale developed by ${ }^{8}$. It was composed of 27 items in total - 3 items in each of 9 sub-areas: Cause analysis, emotional control, impulse control, gratitude, living satisfaction, relationality, optimism, communicative competence and empathy. It was a five-point Likert scale - 1 totally disagree to 5 strongly agree - with a higher score meaning a higher level of resilience. Reliability of 9 areas was Cronbach's a $=.624 \sim .799^{8}$ and in this study is .874 .

\section{Data Collection}

Data were collected from nurses participating in education provided nationwide by branches of the Hospital Nurses Association from January to June 2015 with the approval of the Institutional Review Board (IRB) in $\mathrm{N}$ University (NSU-150310-2). Nurses were given explanation about the purport of research and were asked to give a written consent before questionnaires were distributed. It was a self-administered survey and they were given explanation about confidentiality and anonymity of the collected data and could reject or discontinue the participation at any moment when they didn't want to participate in the research any more.

\section{Data Analysis}

For the collected data, the real number, percentage and the mean and standard deviation were used to assess the general characteristics and values of variables using an SPSS/WIN 21.0 program. T-test and ANOVA were used to determine differences in values of variables by the respondents' general characteristics and Tukey's post hoc test was performed for variables with significant differences, as found by ANOVA. Cronbach's a coefficient was estimated to determine reliability of the instruments and correlation analysis was carried out using Pearson correlation coefficient to determine interrelationship among variables.

\section{Results}

\subsection{General Characteristics}

All participants are women and the mean age of subjects was 25.02 ( \pm 1.99$)$ years. Among them, $96.5 \%$ is unmarried and $93.5 \%$ have three shifts. The average work experience of the subjects is $31.88( \pm 15.24)$ months (Table 1$)$.

Table 1. Characteristics of the participants $(\mathrm{N}=340)$

\begin{tabular}{|l|l|l|}
\hline Characteristics & Categories & $\mathbf{n}(\%)$ \\
\hline \multirow{4}{*}{ Age (yrs) } & $21-25$ & $212(62.4)$ \\
\cline { 2 - 3 } & $26-30$ & $123(36.1)$ \\
\cline { 2 - 3 } & $>31$ & $5(1.5)$ \\
\cline { 2 - 3 } & $\mathrm{M} \pm \mathrm{SD}$ & $25.02 \pm 1.99$ \\
\hline \multirow{4}{*}{ Marriage } & single & $328(96.5)$ \\
\cline { 2 - 3 } & married & $12(3.5)$ \\
\hline & fixed & $209(5.9)$ \\
\cline { 2 - 3 } & shift & $318(93.5)$ \\
\cline { 2 - 3 } & others & $2(0.6)$ \\
\hline
\end{tabular}




\begin{tabular}{|l|l|l|}
\hline \multirow{4}{*}{$\begin{array}{l}\text { Working Period } \\
\text { (mths) }\end{array}$} & $1-12$ & $49(14.4)$ \\
\cline { 2 - 3 } & $13-24$ & $72(21.2)$ \\
\cline { 2 - 3 } & $25-36$ & $81(23.8)$ \\
\cline { 2 - 3 } & $37-48$ & $85(25.0)$ \\
\cline { 2 - 3 } & $49-60$ & $53(15.6)$ \\
\cline { 2 - 3 } & $\mathrm{M} \pm \mathrm{SD}$ & $31.88 \pm 15.24$ \\
\hline
\end{tabular}

\subsection{Association between Resilience and other Factors}

Resilience was positively correlated with job involvement and organizational commitment. It was negatively correlated with emotional labor, turnover intention and burnout as shown in Table 2 .

\subsection{Effects of Resilience on Emotional} Factors

Simple regression analysis for testing the effects of resilience on principal variables for nurses obtained the results as presented in Table 3 .

The variables significantly affected by resilience were emotional labor $(\mathrm{F}=17.30, \mathrm{p}<.001)$, job involvement $(\mathrm{F}$ $=21.53, \mathrm{p}<.001)$, organizational commitment $(\mathrm{F}=28.11$, $\mathrm{p}<.001)$ and burnout $(\mathrm{F}=77.85, \mathrm{p}<.001)$. But resilience had no significant effect on turnover intention.

\section{Conclusion}

Resilience was significantly correlated with emotional labor $(\mathrm{F}=17.30, \mathrm{p}<.001)$ and burnout $(\mathrm{F}=77.85, \mathrm{p}<.001)$.

Table 2. Association between factors $(\mathrm{N}=340)$

\begin{tabular}{|c|c|c|c|c|c|c|}
\hline factor & $\begin{array}{l}1 \\
\mathrm{r}(\mathrm{p})\end{array}$ & \begin{tabular}{|l}
2 \\
$\mathrm{r}(\mathrm{p})$ \\
\end{tabular} & \begin{tabular}{|l|}
3 \\
$\mathrm{r}(\mathrm{p})$ \\
\end{tabular} & \begin{tabular}{|l|}
4 \\
$\mathrm{r}(\mathrm{p})$ \\
\end{tabular} & $\begin{array}{l}5 \\
\mathrm{r}(\mathrm{p}) \\
\end{array}$ & \begin{tabular}{|l}
6 \\
$r(p)$ \\
\end{tabular} \\
\hline $\begin{array}{l}\text { Emotional } \\
\text { labor }\end{array}$ & 1 & & & & & \\
\hline $\begin{array}{l}\text { Turnover } \\
\text { intention }\end{array}$ & $.427^{* *}$ & 1 & & & & \\
\hline $\begin{array}{l}\text { Job } \\
\text { involvement }\end{array}$ & $-.243^{* *}$ & $-.472^{* *}$ & 1 & & & \\
\hline $\begin{array}{l}\text { 4. Organizational } \\
\text { commitment }\end{array}$ & $-.274^{\star \star}$ & $-.620^{* *}$ & $.501^{\star *}$ & 1 & & \\
\hline Burnout & $.545^{\star *}$ & $.582^{\star \star}$ & $-.485^{\star \star}$ & $-.576^{\star *}$ & 1 & \\
\hline 6. Resilience & $-.221^{\star \star}$ & $-.130^{*}$ & $.245^{\star \star}$ & $.277^{\star \star}$ & $-.433^{\star \star}$ & 1 \\
\hline
\end{tabular}

Table 3. Effects of resilience on principal variables

\begin{tabular}{|c|c|c|c|c|c|c|c|c|}
\hline $\begin{array}{l}\text { Dependent } \\
\text { variable }\end{array}$ & & $\begin{array}{l}\text { Independent } \\
\text { variable }\end{array}$ & $\begin{array}{l}\text { Unstandardized } \\
\text { coefficient }\end{array}$ & $\begin{array}{l}\text { Standard } \\
\text { error }\end{array}$ & $\begin{array}{l}\text { Standardized } \\
\text { coefficient }\end{array}$ & $\begin{array}{l}\mathrm{T} \\
\text { (p-value) }\end{array}$ & $\begin{array}{l}\mathrm{F} \\
\text { (p-value) }\end{array}$ & $R^{2}$ \\
\hline \multirow{2}{*}{$\begin{array}{l}\text { Emotional } \\
\text { labor }\end{array}$} & \multirow[t]{10}{*}{$\leftarrow$} & \multirow{10}{*}{$\begin{array}{l}\text { intercept } \\
\text { Resilience }\end{array}$} & 40.466 & 2.475 & & $16.35(<.001)$ & \multirow{2}{*}{$\begin{array}{l}17.30 \\
(<.001)\end{array}$} & \multirow[t]{2}{*}{0.049} \\
\hline & & & -0.110 & 0.026 & -0.221 & $-4.16(<.001)$ & & \\
\hline \multirow{2}{*}{$\begin{array}{l}\text { Turnover } \\
\text { intention }\end{array}$} & & & 19.714 & 1.685 & & $11.70(<.001)$ & \multirow[t]{2}{*}{$5.78(.017)$} & \multirow[t]{2}{*}{0.017} \\
\hline & & & -0.043 & 0.018 & -0.130 & $-2.40(.017)$ & & \\
\hline \multirow{2}{*}{$\begin{array}{l}\text { job } \\
\text { involvement }\end{array}$} & & & 10.992 & 1.799 & & $6.11(<.001)$ & \multirow{2}{*}{$\begin{array}{l}21.53 \\
(<.001)\end{array}$} & \multirow[t]{2}{*}{0.060} \\
\hline & & & 0.089 & 0.019 & 0.245 & $4.64(<.001)$ & & \\
\hline \multirow{2}{*}{$\begin{array}{l}\text { Organizational } \\
\text { commitment }\end{array}$} & & & 20.529 & 4.052 & & $5.07(<.001)$ & \multirow{2}{*}{$\begin{array}{l}28.11 \\
(<.001)\end{array}$} & \multirow[t]{2}{*}{0.770} \\
\hline & & & 0.230 & 0.043 & 0.277 & $5.30(<.001)$ & & \\
\hline \multirow[t]{2}{*}{ Burnout } & & & 110.936 & 5.112 & & $21.70(<.001)$ & \multirow{2}{*}{$\begin{array}{l}77.85 \\
(<.001)\end{array}$} & \multirow[t]{2}{*}{0.188} \\
\hline & & & -0.483 & 0.055 & -0.433 & $-8.82(<.001)$ & & \\
\hline
\end{tabular}


As emotional labor means a process of controlling emotion and expression in pursuit of a business management, emotional labor was found to be factors that affect burnout of nurses ${ }^{-11}$. Social support of hospital nurses had significant mediating effects between emotional labor and burnout ${ }^{9}$. Social support was a more important predictor of emotional labor than self-efficacy of hospital nurses. This finding suggests the importance of social support to increase hospital nurse's psychological well-being and development of organization.

The variables significantly affected by resilience were organizational commitment $(\mathrm{F}=28.11, \mathrm{p}<.001)$. Teacher's resilience and perceived social support have an effect directly on organizational commitment that is, the higher teacher's resilience is the better organizational commitment is growing in order to increase organizational commitment, As a result resilience need to be enforced and make their social support stay high ${ }^{12}$. That study explored the relationships between intensive care unit nurses' resilience, job stress and organizational commitment $t^{\frac{13}{3}}$. Analysis of the relationships between the participants' resilience, job stress and organizational commitment indicated a significantly positive correlation between resilience and organizational commitment $(\mathrm{r}$ $=.45, \mathrm{p}<.001)$. Thus, resilience should be actively promoted and a program developed to enhance the resilience of hospital nurses.

Resilience had no significant effect on turnover intention in this study. It was a different results of previous study said that resilience had a very significant correlation with turnover intention ${ }^{14}$.

A significant relation of resilience and burnout that was shown in this study is agreed with other previous study that was a significant negative correlation between subjects' resilience and burnout $\frac{15}{}$.

The findings of the study indicate that in order to decrease clinical nurses burn out, their resilience to be enhanced. Thus we will recommend the intervention to control clinical nurse's burnout and reduce the turnover rate of clinical nurses and various strategies that will strengthen clinical nurse's resilience and social problem solving abilities will have to be explored.

\section{Acknowledgments}

This research was supported by Namseoul University funded.

\section{References}

1. Cameron F, Brownie S. Enhancing resilience in registered aged care nurses. Australasian Journal of Aging. 2010; 29(2):66-71.

2. Moon SJ, Han SS. A predictive model on turnover intention of nurses in Korea. Journal of Korean Academy of Nursing. 2011; 41(5):633-41.

3. McGloin JM,Widom CS. Resilience among abuse and neglected children grown up. Developmental Psychopathology. 2001; 13:1021-38.

4. Morris JA, Feldman OC. The dimensions, antecedents and consequences of emotional labor. Academy of Management Review.1996; 21(4):986-1010.

5. Kanungo RN. Measurement of job and work involvement. Journal of Applied Psychology. 1982; 67(3):341-9.

6. Pic EH. Correlation study between nurses experienced burnout and job satisfaction degree. [Master's thesis]. Seoul: Yonsei University; 1983.

7. Luther SS, Cicchetti D, Becker B. The construct of resilence: A critical evaluation and guidelines for future work. Child Development. 2000; 71:543-62.

8. Shin WY, Kim MG, Kim JH. Developing measures of resilience for Korean adolescents and testing cross, convergent, and discriminant validity. Korea Adolescent Policy Research. 2009; 20(4):105-31.

9. Kim IS. The role of self-efficacy and social support in the relationship between emotional labor and burn out, turn over intention among hospital nurses. Journal of Korean Academy of Nursing Administration. 2009; 15(4):515-26.

10. Kim DH. The effect that the emotional labor of officials in charge of civil appeal have on exhaustion and job attitude [dissertation]. Daegu: Keimyung University; 2014. p. 1-153.

11. Kim HJ. A study on resilience and emotional labor of agents in call center. [Master's thesis]. Kwangju: Kwangju Women's University; 2012.

12. Lee JY. The relationship between kindergarten and child care teacher's resilience, perceived social support and organizational commitment [dissertation]. Daegu: Catholic University of Daegu; 2012. p. 1-107.

13. Kim MJ. Resilience, social problem-solving ability and burnout in clinical nurses. [Master's thesis]. Daegu: Keimyung University; 2014. p. 1-57.

14. Suh YH. A study on the resilience, job satisfaction and turnover intention of beauty advisors. [Master's thesis]. Seoul: Seokyeong University; 2016. p. 1-92.

15. Kim MJ. The effects of emotional intelligence and emotional labor on burnout, job satisfaction and prosocial service behaviors advisors [Master's thesis]. Seoul: Soongsil University; 2014. p. 1-103. 